\title{
ENERGY-GO-ROUND
}

How did a little Spanish province become one of the world's wind-energy giants? Daemon Fairless reports. 
F rom a wheatfield overlooking the village of Iratxeta in the Spanish region of Navarre, you can appreciate the unique countryside and its contrasts: the pale green of ripening grain setting off the dark-green mountain forests behind, country houses newly rebuilt on medieval foundations, and giant wind turbines, brilliantly white and strikingly erect, their slowly moving blades driven by the breeze that ripples the wheat.

"That was the first one," says José Roman Gómez, pointing south to the Guerinda wind park, a phalanx of turbines running along the ridge of a nearby hill. He draws an arc along the horizon with his finger: "That one was built after. And there is a different one. And, over there, another." Iratxeta, an isolated cluster of stone houses nestled into the hills about 30 kilometres south of the regional capital, Pamplona, is encircled by wind farms. Their turbines loom over the hills like an invading army. But it's an occupation for which Gómez is grateful.

Gómez, who has been managing the local council of the villages of Iratxeta and neighbouring Leoz for the past two decades, is a tranquil and friendly man in his mid-50s. Fifteen years ago, before the wind boom hit this area, the two villages had only about 150 residents between them. "There was no running water here," Gómez explains. "There was no waste collection or buses. Most of the villagers were old and waiting to die."

Now, however, the villages have nearly doubled in size compared with before the wind boom. In addition to providing running water and waste collection, the rent from wind-farm operators has enabled the local council to hire four full-time health workers to care for the community's elderly people. "Now," Gómez says, "people from Pamplona are investing here."

Wind farms have transformed Spain's landscape over the past decade and Navarre, the least populated of the nation's 15 mainland autonomous regions, has been at the forefront. Located in the northeast, between the Basque country and the French border, Navarre generates almost $60 \%$ of its electricity from renewable sources - the vast majority from wind. The region's most recent energy plan, released in May, aims to increase this proportion to more than $75 \%$ by 2010 .

\section{From water to wind}

Although it would hardly be fair to attribute Navarre's renewable-energy boom to just one person, one name invariably arises when discussing wind power, that of Estaban Morrás.

Morrás is the executive director of Acciona Energia, a subsidiary of the Spanish engineering group Acciona, which has grown to be the world's foremost wind-park developer, accord- ing to the Madrid-based Spanish Wind Energy Association, an industry body. Dark-suited and seated behind a boardroom table at the company's headquarters on the outskirts of Pamplona, he looks very much the person you would expect to see running a company with first-quarter revenues in 2007 of $€ 252$ million (US\$337 million). But when Morrás founded the company in 1989, he had more of an Indiana Jones air about him. "I did so much research, running through rivers and forests looking for locations for new hydroelectric projects, my sweaters, my clothes, disintegrated," he says.

Until the early 1990s, small, decentralized hydroelectric stations dotting the rivers that flow out of the Pyrenees were the only significant form of renewable energy in Navarre. Many had been around since early last century, providing power to local small industry.

Morrás founded his company, originally called EHN, with the plan of buying up the existing mini-hydrostations, connecting them to the grid and building more. But it was becoming harder to find new sites. "I spent all year in 1992 desperately looking for new locations," he says. "But it was impossible. I understood my company had no future." But, in 1994, on a trip to France, he saw the future.

"The most significant moment for me," he recalls, "was visiting a wind farm in Montpellier. My first thought was that a single turbine was capable of producing more energy than the last mini-hydro plant we had built. It was really difficult for me to sleep that night." He took to the new technology with gusto and ambition. Morrás says that in his first meeting in the mid1990s with Vestas, the Danish company that he selected as his turbine supplier, he told the then chief executive, Johannes Poulsen, that Spain would have 1,000 megawatts of wind-power capacity by the end of the century. At the time, it had virtually none.

Poulsen, he says, was incredulous: "You are crazy', he told me: 'Denmark has only 400 megawatts after 20 years of effort." Morrás's answer was "with Denmark's experience, we can go faster than you." And they did. With 11,615 megawatts of installed wind capacity at the end of last year, Spain is second in the world to Germany in capacity, beating the United States by just 39 megawatts (see graphic, overleaf).

The energy actually generated is much less, however, thanks to the caprice of the wind and maintenance downtime for the turbines. The
23,372,000 megawatt-hours generated in 2006 is only $23 \%$ of the turbines' full capacity. Nevertheless, it provided just over $8.5 \%$ of Spain's electricity: only Denmark boasts a higher percentage. On a particularly blustery day this March, wind generation was providing 27\% of Spain's electricity supply - surpassing, for a fleeting moment, the contributions of both nuclear and coal-fired plants.

\section{Power to the people}

The wind boom in Navarre is among the most intensive in Spain. Throughout the 1980s and 1990s, the government of Navarre was eager to develop new industries, especially as the region seemed overly dependent on its single large industrial employer, a Volkswagen car plant. But with a limited local power supply, Navarre's infrastructure wasn't particularly appealing to outside investors. Morrás's wind-power plan offered a solution, and promised an industry in its own right - more enticing for the government at the time than any environmental argument.

Well before Spain's national government started to guarantee profitable prices for selling wind-generated power to utilities, Navarre had bought into Morrás's vision. His first wind farm, El Perdón, was built south of Pamplona in 1994; since then the government of Navarre has approved well over a thousand turbines in 32 wind farms. From 1995 to 2004, it invested more than $€ 136$ million in renewable-energy enterprises, contributing up to $30 \%$ of the initial funding and providing tax credits for investors. The current renewable-energy plan (2005-2010) has earmarked an extra $€ 240$ million for investment in renewables. Navarre's installed wind capacity is about 950 megawatts $-8.5 \%$ of the country's total on $2 \%$ of its land, and nearly two-thirds that of its neighbour, France.

For a while it looked as though Navarre might become entirely self-sufficient by 2010 , producing as much electricity through renewables as it consumed. "Our goal in this area was more aggressive than it is now," admits José Javier Armendáriz, the region's minister of industry, technology, commerce and labour.

Morrás's aspirations haven't changed, however. "I think it's possible for Navarre to obtain $100 \%$ of its energy with renewables," he says. "This project is essentially one of companies and people in the private sector. I don't understand the position of the government. The target 
for me is to obtain 100\%." His goals to expand renewable energy go well beyond the region. "I am convinced that it is possible for the world to have an energy model that is $100 \%$ renewable."

Navarre could do nicely out of this. By 2003 the region had more than 50 companies active in various aspects of renewable energy (J. Faulin et al. Energy Policy 34, 2201-2216; 2005), and that year it was commended as having the best regional policy in Europe at the European Conference for Renewable Energy in Berlin. EHN became lucrative enough to attract the attention of the Acciona Group, which after first taking a small stake, took it over entirely in 2005. The Navarrese wind boom also gave birth to Gamesa Eólica in Pamplona, initially created as a local supplier for EHN, which has grown to be one of three turbine producers vying with each other for second place to Vestas in the world turbine market.

Pamplona is on its way to becoming the official hub of Spanish renewable energy. The city is home to the National Renewable Energy Centre, a new research facility that focuses on developing commercial applications in wind, solar and bioenergy, and to two national training facilities in renewable technologies. Last autumn, the Public University of Navarre in Pamplona launched the country's first graduate programme for electrical engineers in wind and solar electricity, to meet the growing demand for specialists.

\section{Running out of land}

The region's success has led it into uncharted waters, however. Although much of the rest of the world is still waking up to renewables, Navarre has reached possible saturation point, at least for wind power. In 2004, the regional government stopped approving proposals for new

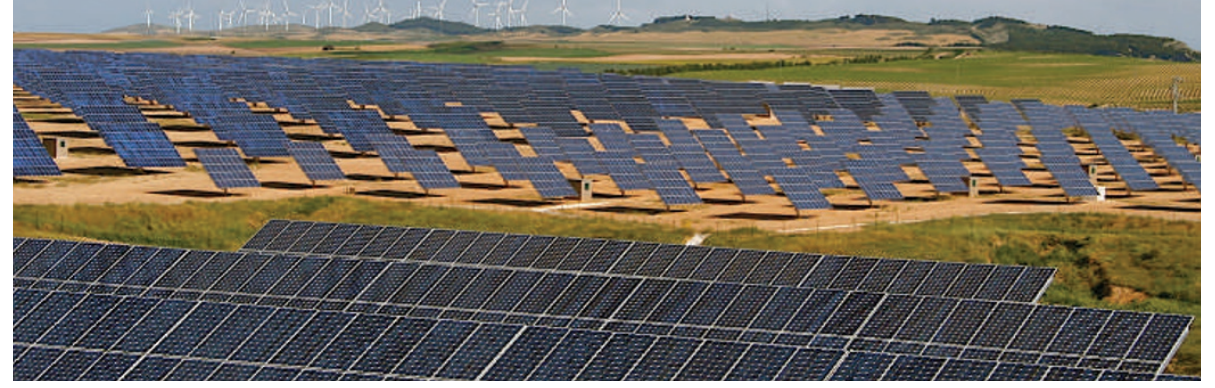

Solar panels and wind farms have helped to regenerate the entire Navarre region.

wind farms. One reason, it says, is the effect on the landscape. According to Armendáriz, the government sensed that further development might lose it the public support that, he says, was one of the reasons wind power could gain such traction in the region.

Another reason is that wind-power capacity can grow without building new farms, by installing newer, higher-capacity turbines. Several of the region's first wind parks, those with 500-kilowatt machines, will be fitted with newer 3-megawatt models, starting this summer.

Even so, having so much wind energy contributing to the network comes with technical concerns. The amount of energy that each wind turbine produces depends entirely on what the wind is doing, and can vary from moment to moment. This makes it difficult for power utilities, which need to match the amount of energy generated with the amount being consumed moment-by-moment.

If you rely on wind power, you need spare capacity for when the wind drops, and in 2004, when new farms stopped being developed, the regional government approved two 400-megawatt natural-gas plants near Castejón, a town in southern Navarre. Luis María López González, an engineer specializing in renewable energy at

\section{THE POWER OF THE WIND}

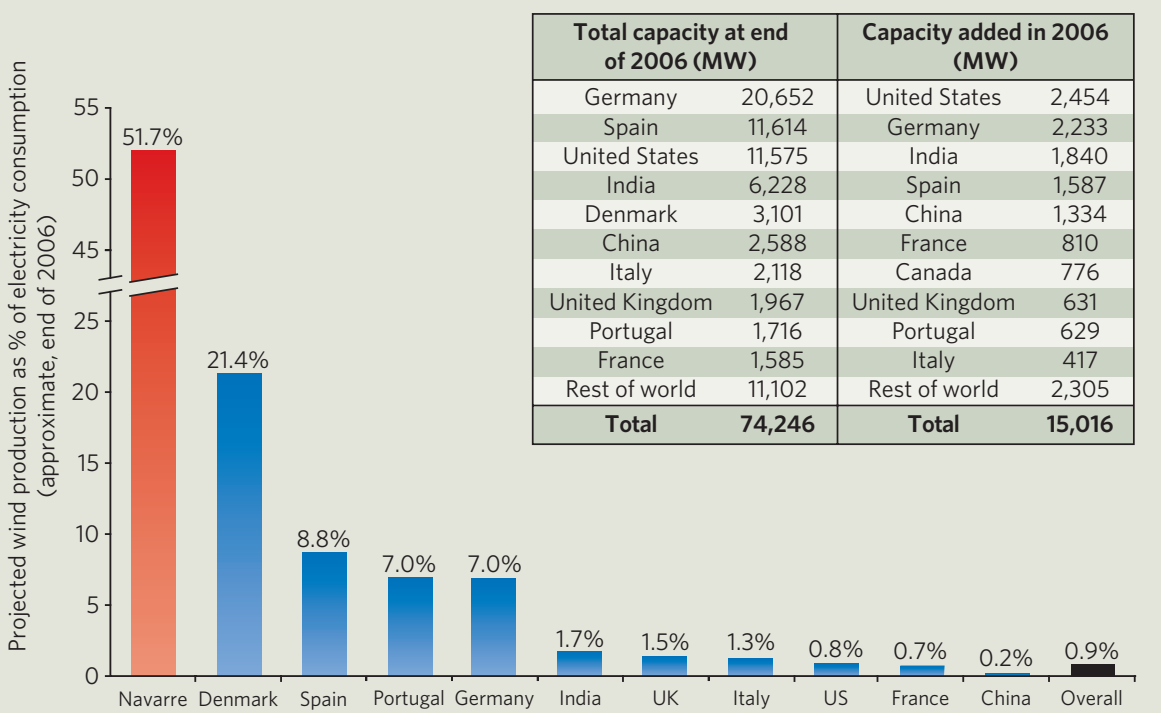

the University of La Rioja in Logroño, suggests that the intermittent nature of wind generation was one of the reasons that the plants were built. These 'combined-cycle' plants, which harness their own waste heat, can be fired up quickly to meet a sudden need. They are also efficient, emitting a little over half of the carbon dioxide per watt that a coal-powered plant does. But that's still a lot more carbon dioxide than a windmill.

With the wind sector maturing, Spain as a whole is starting to look elsewhere for renewable-energy sources. Last month, the national parliament lowered the subsidies that wind operators get and boosted subsidies for the production of biomass and biofuels and solar photovoltaics. One new scheme is so-called 'solar gardens', large expanses of solar panels in which individual investors can buy as few as a single panel, enjoying both the income it provides and the feeling that they are greening the grid.

Morrás has no complaints about the government shifting funds away from wind and into other forms of renewable energy, even though it means that making a profit from wind is harder. "It will be an effort for the sector," he says, "but we can do it." And there is still plenty of room for wind-farm growth elsewhere. "In my opinion," he says, "the next years will be the most important, with the extension of wind farms in China, India, South America, Europe and Russia."

Closer to home, in Iratxeta, Gómez has been overseeing a more modest expansion - the erection of a new building for the village council, one of several infrastructure projects the village has invested in with the income they receive from the wind parks.

For Gómez, wind power is a renewal as well as a renewable: it has brought Iratxeta and its neighbouring villages back from what seemed to be an inevitable decline. He is disappointed with the government's decision to make no new wind parks. "I think if you ask people around here," he says, "they'll tell you they want more because it means more money. Wind power," he says with the emphasis of someone who has seen science change his world for the better, "has been a copernican revolution."

Daemon Fairless is this year's winner of the IDRC-Nature fellowship. 